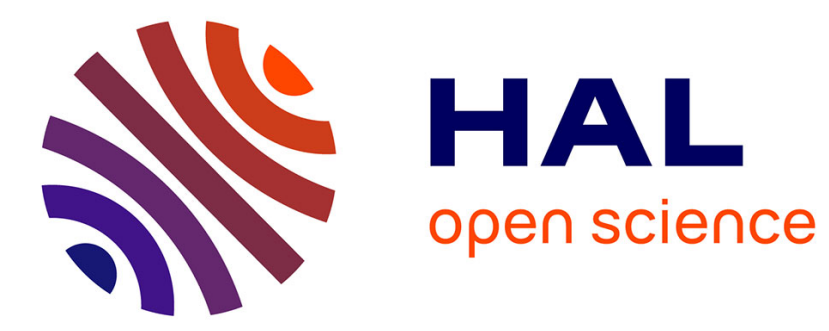

\title{
Lay Theories About White Racists: What Constitutes Racism (and What Doesn't)
}

\author{
Samuel R. Sommers, Michael I. Norton
}

\section{To cite this version:}

Samuel R. Sommers, Michael I. Norton. Lay Theories About White Racists: What Constitutes Racism (and What Doesn't). Group Processes and Intergroup Relations, 2006, 9 (1), pp.117-138. 10.1177/1368430206059881 . hal-00571619

\section{HAL Id: hal-00571619 https://hal.science/hal-00571619}

Submitted on 1 Mar 2011

HAL is a multi-disciplinary open access archive for the deposit and dissemination of scientific research documents, whether they are published or not. The documents may come from teaching and research institutions in France or abroad, or from public or private research centers.
L'archive ouverte pluridisciplinaire HAL, est destinée au dépôt et à la diffusion de documents scientifiques de niveau recherche, publiés ou non, émanant des établissements d'enseignement et de recherche français ou étrangers, des laboratoires publics ou privés. 


\title{
Lay Theories About White Racists: What Constitutes Racism (and What Doesn't)
}

\author{
Samuel R. Sommers \\ Tufts University
}

Michael I. Norton
Harvard Business School

Psychological theories of racial bias assume a pervasive motivation to avoid appearing racist, yet researchers know little regarding laypeople's theories about what constitutes racism. By investigating lay theories of White racism across both college and community samples, we seek to develop a more complete understanding of the nature of race-related norms, motivations, and processes of social perception in the contemporary United States. Factor analyses in Studies 1 and la indicated three factors underlying the traits laypeople associate with White racism: evaluative, psychological, and demographic. Studies 2 and 2a revealed a three-factor solution for behaviors associated with White racism: discomfort/unfamiliarity, overt racism, and denial of problem. For both traits and behaviors, lay theories varied by participants' race and their race-related attitudes and motivations. Specifically, support emerged for the prediction that lay theories of racism reflect a desire to distance the self from any aspect of the category 'racist'.

KEYWORDS distancing, intergroup relations, lay theories, modern racism, racial attitudes, social perception, stereotyping

Even though it might appear otherwise from what I've said, I am not a racist. (John Rocker, 'Rocker apologizes', 1999)

ONE would hesitate before calling John Rocker-the baseball pitcher whose offensive remarks about immigrants and various racial groups were published in Sports Illustrated several years ago-an astute commentator on contemporary social mores. However, his quotation above suggests three conclusions regarding lay theories of White racism in the United States, all of which are explored in the present investigation. First, by claiming that his actions do not reflect his beliefs, Rocker's statement demonstrates the ambiguity and subjectivity of determinations of racism. Second, his quotation clearly indicates that Rocker, despite having previously voiced negative sentiment

\section{Author's note}

Address correspondence to Samuel R.

Sommers, Tufts University, Department of Psychology, 490 Boston Avenue, Medford, MA 02155, USA [email: sam.sommers@tufts.edu] 
toward members of certain racial groups, wishes to distance himself from the label 'racist'. Third, Rocker's comments indicate an awareness that the general public associates certain behaviors and characteristics with racism; he knows that in light of his published remarks, many will view him as a member of this category 'racist.'

On these first two observations, psychologists have written volumes. The subjectivity of determinations of racism has been conveyed, for example, by studies of attributional ambiguity (e.g. Crocker, Voelkl, Testa, \& Major, 1991). Debate over the measurement and nature of racial bias (see Banaji, Nosek, \& Green, 2004; Biernat \& Crandall, 1999; Karpinski \& Hilton, 2001) further illustrates the complexities surrounding attempts to study racism. As for the second point-Rocker's desire to avoid the label 'racist'-numerous researchers have demonstrated that contemporary Whites are often influenced by the motivation to appear nonprejudiced (e.g. Dunton \& Fazio, 1997; Fein, Morgan, Norton, \& Sommers, 1997; Norton, Vandello, \& Darley, 2004; Plant \& Devine, 1998).

But on the third observation above, that there are specific characteristics and behaviors that laypeople associate with White racism, psychologists have not commented extensively. In this article, we investigate lay theories of White racism by addressing basic questions including the following: What is the nature of lay theories of racism? Do these theories vary across samples? What motivational processes affect the content of these theories, and what individual differences correlate with them? By adopting a lay theories perspective on White racism, the present research attempts to achieve a more complete understanding of the salient beliefs, norms, and motivations that impact interracial perceptions and intergroup relations in everyday life.

\section{Why study lay theories of racism?}

Many psychological theories of racism grow out of the assumption that individuals are motivated by a desire to be, or at least appear to be nonprejudiced (Devine, 1989; Gaertner \& Dovidio, 1986; Kinder \& Sears, 1981). In fact, as alluded to in the opening to this article, few social categories in this day and age seem to be as aversive as that of 'racist' (Crandall, Eshelman, \& O’Brien, 2002). Nonetheless, psychologists have only a superficial understanding of this category that so many individuals are purportedly trying to avoid at all costs. We believe that approaching racism from a lay theories perspective is likely to be fruitful in the effort to develop a deeper understanding of the behaviors and characteristics that lead to controversy and intergroup conflict in contemporary society. The concept of the lay theory has been defined as an 'organized knowledge structure that directs behavior, judgments, and evaluations' (Cameron, Alvarez, Ruble, \& Fuligni, 2001, p. 118), suggesting that an examination of lay theories of White racism will provide a more complete picture of the nature and antecedents of contemporary prejudice and discrimination.

The present investigation continues the recent movement in the literature towards a fuller consideration of racism. Historically, research on stereotyping and prejudice has focused on the attitudes, motivations, and behavior of perceivers. That is, studies typically examine how people think about and act toward members of stigmatized groups. More recently, though, psychologists have begun to examine the experiences and perceptions of targets (e.g. Landrine \& Klonoff, 1996; Shelton, 2000; Swim, Cohen, \& Hyers, 1998). By breaking from the traditional perspective on the perceiver/target dichotomy, these studies contribute to a richer understanding of racism. We hope to accomplish a similar goal by turning these proverbial tables once more. The present studies place biased perceivers in the role of targets, exploring the characteristics and behaviors typically associated with them. In doing so, this investigation will shed light on the factors that influence determinations of racism and the specific ways in which people attempt to present themselves as nonprejudiced.

Beyond the domain of racism, this line of inquiry also contributes to the general lay 
theories approach in psychology. Research on the role of lay theories in social perception suggests that the purposes of such theorizing include the effort to make sense of complicated information and construct a meaningful social reality (e.g. Hong, Levy, \& Chiu, 2001; Levy, Plaks, Hong, Chiu, \& Dweck, 2001; Lickel, Hamilton, \& Sherman, 2001). Certainly, these functions are served by lay theories about White racism, but we suggest an important caveat: Based on contemporary psychological theories-and spelled out in more detail below-we suggest that lay theories of racism serve to create a social reality that is informative, but also nonthreatening. Because of the uniquely polarizing and controversial nature of ideas about race, we propose that people's theories of racism tend to be constructed in ways that allow them to maintain a safe distance from any appearance of personal bias. In this respect, the present investigation has the potential to broaden the scope of our understanding and expectations regarding the function of lay theories in social perception and intergroup relations.

\section{Content of lay theories of racism}

Psychologists know few specifics about lay theories of racism, but one conclusion of previous research is that White-on-Black discrimination is considered to be the prototypical form of racial bias (Inman \& Baron, 1996; Rodin, Price, Bryson, \& Sanchez, 1990). In light of this result, we focused the present research on lay theories regarding White racism, and in particular, on the traits and behaviors people associate with White racists. With respect to traits, one possibility is that lay theories reflect actual correlates of racial bias, such as authoritarianism, impulsivity, and indifference to social norms (Adorno, Frenkel-Brunswick, Levinson, \& Sanford, 1950; Gough \& Bradley, 1993). The recent distinction drawn by psychologists between 'old-fashioned' racism and a modern, subtle form of bias also suggests possibilities for the content of lay theories regarding racism. Traits epitomizing the concept of old-fashioned racism could include 'aggressive' or 'violent', or demographics such as 'red-necked' or 'Southern'. That modern racists can act nonprejudiced while still harboring biased beliefs could lead to trait associations such as 'devious' or 'dishonest'.

This distinction between old-fashioned and modern racism may also be apparent in people's theories about behaviors typical of White racists. Old-fashioned behaviors could include violence toward a person because of race or use of racial epithets in conversation. Behaviors typical of a modern racist could include opposing affirmative action or feeling uncomfortable around people of another race. Yet another possibility is that, just as psychologists distinguish between prejudice, discrimination, and stereotyping, lay theories about racist behaviors will be marked by distinctions between affect, overt acts, and cognition. In sum, there are multiple plausible predictions for the specific content of lay theories of racism, an empirical question that has not been explored previously by psychologists.

\section{Racial differences in lay theories}

Determinations of racism are subjective, and therefore a thorough exploration of lay theories also requires examination of the ideologies, motivations, and demographics correlated with race-related judgments (see Khan \& Lambert, 2001). Therefore, another goal of the present studies was to identify individual differences that predict lay theories of racism. We expect that, on average, White and non-White participants tend to endorse different aspects of lay theories regarding White racism. Given that non-White individuals are more likely to have experienced racial prejudice, they may hold stronger negative attitudes toward racists and be more likely than Whites to label ambiguous behaviors as indicative of racism. Empirical evidence of between-race differences in racial attitudes and judgments supports this prediction (e.g. Johnson, Simmons, Trawalter, Ferguson, \& Reed, 2003; Monteith \& Spicer, 2000; Sommers \& Ellsworth, 2000). Not only would such between-race differences be of theoretical interest, but they would also have 
real-world applications for attempts to predict and reconcile social conflict borne from allegations of racism.

Racial differences such as these may signify more than differential sensitivity to racism among Whites and non-Whites; such effects could also indicate self-protective concerns on the part of White participants. Previous research has demonstrated that people are motivated to distance their own attitudes and personalities from those belonging to members of undesirable social categories (Hodson \& Esses, 2002; Schimel, Pyszczynski, Greenberg, O'Mahen, \& Arndt, 2000). For example, Wood, Pool, Leck, and Purvis (1996) found that participants modified their own attitudes when they believed them to be shared by members of the Ku Klux Klan. Thus, between-race differences in theorizing about racism may also indicate the extent to which Whites are motivated to avoid classifying themselves as racists. Few contemporary social categories are as undesirable as that of 'racist', and Whites' concerns about self-classifying as such might lead to narrower, less inclusive conceptualizations of racism.

\section{Psychological predictors of lay theories}

In order to examine this variability in how people theorize about racism and to test our self-distancing hypothesis, the present investigation includes measures of participants' racial attitudes and race-related motivations. Perhaps the most frequently used measure of explicit racial attitudes is the Modern Racism Scale (MRS; McConahay, 1986), which assesses beliefs associated with subtle forms of racism. We expected that the relationship between the MRS and lay theories about White racism would be strongest for ratings of the specific traits and behaviors that high-MRS individuals themselves are likely to exhibit. More precisely, high-MRS participants were expected to be particularly unlikely to theorize about White racism using those ideological characteristics or ambiguously biased behaviors that are traditionally associated with their own race-related value systems and political beliefs. By conceptualizing racism more narrowly as an overt, blatant set of responses, high-MRS individuals can assert to others-and themselves-that they do not belong to this aversive category.

We also included measures of race-related motivations. Plant and Devine (1998) describe high scores on their Internal Motivation to respond without prejudice Scale (IMS) as deriving from personal beliefs that bias is wrong. We expected this belief system to predict endorsement of the theory that racism results from intrinsic factors. Specifically, we believed that high-IMS individuals would associate ideological and psychological characteristics with White racism, and would demonstrate a propensity for inferring racism from ambiguous behaviors. Absent additional insight into a actor's intentions, high-IMS participants should be likely to assume, for example, that a White person who tells racist jokes does so because of racist beliefs, or that a White who only dates Whites harbors a racial preference. In sum, we predicted that high-IMS individuals, whose own perceptions and actions are influenced by internal values, would focus on intrinsic causes in theorizing about the race-related behavior of others.

Conversely, people who score high on the External Motivation Scale (EMS) seek to avoid racial bias because of extrinsic pressures such as political correctness and fear of reprisal (Plant \& Devine, 1998). Therefore, we expected highEMS individuals to focus less on internal causes of racial bias and to be more sensitive to situational determinants of racism. As opposed to an ideological or psychological basis for White racism, high-EMS individuals were expected to endorse a more external, superficial conceptualization. For example, we expected that highEMS participants would depict racists in demographic terms and would be relatively unlikely to perceive ambiguous behaviors as indicative of racism. Because of their heightened awareness of the situational determinants of race-related behavior, high-EMS individuals should be likely to conclude, for instance, that someone who tells racist jokes is succumbing to social pressure, or that a White who only dates 
other Whites simply lives in a homogeneous community. In other words, we expected the same sensitivity to external factors that marks the race-related behavior of high-EMS individuals to color their theories about racial bias in general.

\section{Overview of the present investigation}

This research was designed with three objectives: (1) to identify the specific traits and behaviors that comprise lay theories of White racism; (2) to identify reliable factor structures underlying these theories; (3) to measure the associations between these factors and individual differences such as race, racial attitudes, and racerelated motivations. In Study 1, we examine the specific content of lay theories about racist traits and use exploratory factor analysis to identify the structure underlying these theories. In Study 2, we examine lay theories regarding racist behaviors in the same manner. In both of these investigations, regression analyses assess the relationship between race-related individual differences (i.e. participant race; MRS, IMS, EMS scores) and participants' theories about White racists (i.e. factor scores). Studies $1 \mathrm{a}$ and 2a replicate the factor structures of Studies 1 and 2 using noncollege-student samples.

\section{Study 1}

\section{Method}

Trait generation We initially asked 21 college students to provide up to five responses to the following question: 'Think about the category "White racist". What traits or characteristics do you associate with it?' A list of 48 descriptors, each of which had been listed by three or more participants, was shown to judges blind to the objectives of the study for the purpose of combining redundant items. Contradictory items (e.g. 'intelligent' and 'unintelligent') were left unchanged. This process generated a final list of 40 items (see Table 1).

Participants A total of 229 undergraduate psychology students at two Universities in the
Northeast US completed the final questionnaire in mass testing sessions in exchange for course credit or as part of a classroom exercise. Of these participants, $161(70.3 \%)$ identified as White, $21(9.2 \%)$ as Black, $27(11.8 \%)$ as Asian, $19(8.3 \%)$ were distributed across other racial categories, and $1(0.4 \%)$ did not indicate race, ${ }^{1}$ 109 participants $(47.6 \%)$ were female, 119 $(52.0 \%)$ were male, and $1(0.4 \%)$ did not indicate gender.

Materials The final questionnaire consisted of two sections. The trait section began with the following instructions: 'Think about the following category: 'racist White people'. Please use the scale below to respond to the statements that follow'. A 21-point scale was provided $(1=$ 'strongly disagree', $11=$ 'neutral', 21 = 'strongly agree') and the 40 traits followed in random order, each preceded by the phrase 'Racists tend to be ...'. The other section assessed participants' race, racial attitudes, and race-related motivations. Six items from the MRS (McConahay, 1986) were included; the item pertaining to school integration was deleted because pretesting indicated that participants were largely unfamiliar with this issue. We also included Plant and Devine's (1998) Internal/ External Motivation to respond without prejudice Scales. The IMS consists of five items (e.g. 'I attempt to act in nonprejudiced ways toward Black people because it is personally important to me'), as does the EMS (e.g. 'I try to hide any negative thoughts about Black people in order to avoid negative reactions from others').

The order of the trait and individual difference sections of the questionnaire was counterbalanced. Scores for the factors described below, the MRS, and the IMS did not differ by questionnaire order $(t \mathrm{~s}(224)<1.20, n s)$. An order effect for EMS scores-which were higher in the trait-first than in the trait-second condition-appeared to result from different proportions of non-White participants in the two order conditions. Analyzing only the responses of Whites revealed no order effect for the EMS $(t(158)<1)$. 
Group Processes $\mathcal{E}$ Intergroup Relations 9(1)

Table 1. Means and standard deviations for racist traits in Studies 1 and 1a

\begin{tabular}{|c|c|c|c|c|}
\hline \multirow[b]{2}{*}{ Trait } & \multicolumn{2}{|c|}{ Study 1} & \multicolumn{2}{|c|}{ Study la } \\
\hline & $M$ & $S D$ & $M$ & $S D$ \\
\hline closed-minded & 18.97 & 3.02 & 17.86 & 4.52 \\
\hline stubborn & 17.69 & 3.23 & 16.52 & 4.24 \\
\hline opinionated & 17.31 & 4.16 & 16.97 & 4.54 \\
\hline ignorant & 16.08 & 4.41 & 15.61 & 5.59 \\
\hline fearful of change & 15.95 & 4.05 & 15.47 & 4.66 \\
\hline hateful & 15.47 & 4.18 & 15.86 & 4.75 \\
\hline conservative & 14.77 & 4.86 & 13.22 & 5.34 \\
\hline insecure & 14.76 & 4.67 & 14.71 & 4.80 \\
\hline insensitive & 14.52 & 4.51 & 14.33 & 5.02 \\
\hline presumptuous & 14.34 & 4.31 & 14.72 & 4.77 \\
\hline lacking in empathy & 14.34 & 4.51 & 13.75 & 5.32 \\
\hline old-fashioned & 14.23 & 4.83 & 13.89 & 5.03 \\
\hline arrogant & 14.13 & 3.90 & 13.73 & 5.32 \\
\hline naive & 14.04 & 4.49 & 13.65 & 5.47 \\
\hline sheltered & 13.43 & 4.14 & 12.26 & 5.47 \\
\hline selfish & 13.00 & 4.12 & 12.80 & 4.87 \\
\hline immoral & 12.98 & 4.82 & 12.33 & 5.23 \\
\hline cruel & 12.60 & 4.40 & 13.54 & 5.06 \\
\hline Southern & 12.51 & 4.26 & 11.35 & 5.39 \\
\hline uneducated & 12.38 & 4.47 & 11.92 & 5.49 \\
\hline excitable & 12.37 & 3.39 & 12.13 & 4.54 \\
\hline low in self-esteem & 12.36 & 4.56 & 12.82 & 5.13 \\
\hline aggressive & 12.23 & 3.99 & 12.71 & 4.60 \\
\hline male & 12.00 & 3.78 & 10.95 & 5.17 \\
\hline envious & 11.92 & 4.26 & 11.86 & 5.14 \\
\hline cold & 11.84 & 4.96 & 12.44 & 5.07 \\
\hline old & 11.61 & 3.90 & 10.37 & 4.95 \\
\hline unintelligent & 11.60 & 5.08 & 11.52 & 5.90 \\
\hline religious & 11.57 & 4.11 & 11.41 & 4.98 \\
\hline violent & 11.28 & 4.38 & 12.59 & 4.63 \\
\hline unfriendly & 11.07 & 4.37 & 11.73 & 4.53 \\
\hline serious & 11.04 & 4.01 & 11.68 & 4.57 \\
\hline devious & 10.88 & 4.05 & 11.20 & 4.80 \\
\hline self-confident & 10.67 & 4.55 & 10.43 & 5.25 \\
\hline sneaky & 10.34 & 3.57 & 10.69 & 4.50 \\
\hline poor & 10.21 & 4.23 & 10.02 & 4.71 \\
\hline untrustworthy & 10.20 & 4.73 & 10.93 & 5.12 \\
\hline calm & 9.03 & 3.15 & 9.34 & 4.35 \\
\hline intelligent & 8.95 & 3.27 & 9.82 & 4.72 \\
\hline wealthy & 8.79 & 3.81 & 9.22 & 4.55 \\
\hline
\end{tabular}

Notes: Values based on responses to the following statement: 'Racists tend to be (insert trait here)'. Responses were made on a scale of 1-21, where 1 = 'strongly disagree', $11=$ 'neutral', and 21 = 'strongly agree'. $N=229$ (Study 1); $N=242$ (Study 1a). 


\section{Results and discussion}

Trait descriptives Means and standard deviations for participants' ratings of the 40 trait items are presented in Table 1. Comparisons between White and non-White participants indicated that their responses differed significantly for six items: 'arrogant', 'devious', 'opinionated', 'sneaky', 'untrustworthy', and 'violent' $(t \mathrm{~s}(226)>2.17, p \mathrm{~s}<.05)$. In each case, as expected, non-White participants rated the item as more typical of racists than White participants did.

Factor analysis Exploratory factor analysis was performed on the trait data using principal components extraction and direct quartimin (oblique) rotation. Analysis of the scree plot indicated a three-factor solution (Cattell, 1966), accounting for $38.6 \%$ of the explained variance. This pattern matrix is presented in Table 2, with a loading of .45 used as the cut-off for interpretation (Tabachnick \& Fidell, 1996). Interfactor correlations were .36 for Factors 1 and 2, .16 for Factors 1 and 3, and -.06 for Factors 2 and 3. Factor scores were computed using the regression method.

Factor 1 accounted for $25.1 \%$ of the variance explained, with 15 items loading at .45 or higher. The mean response for these items was 12.1 with an average standard deviation of 4.30 . These traits range from 'excitable' and 'aggressive' to 'cold' and 'cruel', but each item reflects a clearly negative evaluation of racism. Aspects of both overt, old-fashioned racism and subtle, modern racism can be seen in this factor. Racists are described as 'violent' and 'hateful', but also as 'devious' and 'untrustworthy'. This evaluative factor conveys a negative evaluation of the intellect, morality, and temperament of racists, essentially comprising a broad stereotype of the category 'White racist'.

Factor 2 accounted for $7.6 \%$ of the variance explained, with six items loading at .45 or higher. Their average rating was 15.7 with an average standard deviation of 4.25 , indicating that participants believed these traits to be more typical of racists than the Factor 1 (or Factor 3) traits. The Factor 2 traits do not have a strictly evaluative connotation, but rather describe psychological or cognitive tendencies of racists, such as 'old-fashioned' and 'closedminded'. These traits represent inferences drawn about the mental processes and motivations of White racists (e.g. 'fearful of change,' 'insecure'), and judgments regarding the veracity of racist ideologies (e.g. 'ignorant,' 'naïve').

Factor 3 accounted for $5.1 \%$ of the variance explained, with six items loading at .45 or higher. The mean response for these items was 11.2 with an average standard deviation of 3.78. In general, these traits comprise an extrinsic, demographic depiction of racism, identifying White racists as 'Southern', 'old', 'religious', 'wealthy,' and 'sheltered.' This factor is reminiscent of the perpetrators of old-fashioned, overt racism or, as Gaertner and Dovidio (1986) have suggested, 'red-necked' racism.

Individual differences For each of the three trait factors, scores were first regressed on a participant race variable $(0=$ non-White participant, $1=$ White participant). MRS, IMS, and EMS scores were then added to the regression model. ${ }^{2}$ The combination of Asian, Black, Latino, and other participants into one category of 'non-White' is an analytic strategy with obvious limitations. Members of different racial groups have likely had very different experiences with racism, and the label 'nonWhite' is not intended to suggest otherwise. However, given the participant population in the present studies, meaningful analysis by specific racial group was not possible. Moreover, the present research examines lay theories about White racists, and comparing the responses of potential ingroup members (e.g. Whites) and outgroup members (e.g. individuals who are not White) is therefore informative. Nonetheless, future investigation using larger numbers of participants from a variety of racial groups is advisable.

The evaluative factor was the only factor for which the between-race difference in participant scores approached significance $(\beta=-.12$, $p=.07)$. This negative coefficient indicated that non-White participants gave marginally higher ratings to these items than did Whites, 
Group Processes E Intergroup Relations 9(1)

Table 2. Pattern matrix factor loadings for traits associated with racism in Study 1

\begin{tabular}{|c|c|c|c|}
\hline Trait & $\begin{array}{c}\text { Factor } 1 \\
\text { (evaluative) }\end{array}$ & $\begin{array}{c}\text { Factor } 2 \\
\text { (psychological) }\end{array}$ & $\begin{array}{c}\text { Factor } 3 \\
\text { (demographic) }\end{array}$ \\
\hline violent & .79 & -.03 & -.09 \\
\hline unfriendly & .79 & -.14 & .07 \\
\hline cruel & .77 & .05 & .02 \\
\hline aggressive & .75 & -.01 & .11 \\
\hline devious & .74 & -.14 & .15 \\
\hline excitable & .68 & -.10 & .15 \\
\hline cold & .66 & .01 & -.16 \\
\hline untrustworthy & .66 & .06 & .02 \\
\hline insensitive & .63 & .13 & -.17 \\
\hline sneaky & .62 & -.10 & .19 \\
\hline serious & .61 & .07 & -.06 \\
\hline selfish & .52 & .19 & -.11 \\
\hline unintelligent & .51 & .20 & -.02 \\
\hline immoral & .50 & .18 & -.07 \\
\hline hateful & .50 & .28 & -.07 \\
\hline poor & .44 & -.01 & .20 \\
\hline arrogant & .38 & .21 & .04 \\
\hline presumptuous & .37 & .25 & .06 \\
\hline lacking in empathy & .36 & .27 & -.03 \\
\hline male & .36 & -.23 & .34 \\
\hline envious & .33 & .28 & -.00 \\
\hline opinionated & .30 & .27 & -.25 \\
\hline old-fashioned & .00 & .70 & .11 \\
\hline fearful of change & -.03 & .69 & -.08 \\
\hline ignorant & .04 & .67 & .29 \\
\hline insecure & .12 & .65 & -.11 \\
\hline naive & -.01 & .54 & .21 \\
\hline closed-minded & .09 & .52 & -.16 \\
\hline stubborn & .22 & .43 & -.31 \\
\hline low in self-esteem & .24 & .41 & -.03 \\
\hline conservative & .19 & .38 & .24 \\
\hline sheltered & -.06 & .46 & .54 \\
\hline old & .05 & .07 & .49 \\
\hline Southern & .29 & .0 & .48 \\
\hline wealthy & .17 & -.08 & .48 \\
\hline religious & .21 & .07 & .46 \\
\hline calm & -.24 & .07 & .46 \\
\hline uneducated & .30 & .34 & .38 \\
\hline intelligent & -.28 & -.15 & .31 \\
\hline self-confident & .29 & -.30 & .31 \\
\hline
\end{tabular}

Notes: $N=229$. Factor loadings of .45 and above are in bold.

supporting the prediction that non-Whites would report a more negative impression of the category 'racist'. When the MRS, IMS, and EMS were added to the regression model, none of these individual difference measures emerged as significant predictors of evaluative factor scores (respective $\beta \mathrm{s}=-.06,-.01, .06, p \mathrm{~s}>.44$ ) These Factor 1 traits seem to comprise a broad, 
consensus view of White racists that did not differ by the race-related attitudes or motivations assessed in this study.

Unlike the evaluative factor, participant race did not significantly predict scores for the psychological factor $(\beta=-.06)$. However, when added to the regression model, both the MRS $(\beta=-.20, p<.01)$ and IMS $(\beta=.26, p<.001)$ emerged as significant predictors of these factor scores, as expected; the EMS did not $(\beta=.05)$. The MRS results are consistent with the prediction that lay theories of racism reflect people's desire to distance themselves from the category 'racist'. High MRS scores were not simply associated with a general tendency to resist labeling traits as typical of White racists, but rather the negative correlation between MRS scores and trait ratings was limited to those items that loaded on this psychological factor. Given that the MRS is a measure of political beliefs, high-MRS participants may have been particularly wary of labeling as typical of racists psychological or ideological traits because doing so could have led to selfcategorization as a racist. Further evidence of the relationship between personal race-related motivations and general theories about racism is provided by the positive association of IMS and psychological factor scores. These data supported the prediction that the stronger participants' own internal motivation to avoid prejudice, the more likely they would be to theorize about White racism using intrinsic traits related to psychological tendencies.

Participant race also failed to predict scores for the demographic factor $(\beta=.00)$. When added to the regression, neither the MRS nor IMS predicted scores for this factor (both $\beta \mathrm{s}=$ $.02)$, but EMS scores did $(\beta=.20, p<.005)$. As predicted, the higher participants scored on the EMS, the more likely they were to theorize about racism using extrinsic, superficial descriptors such as demographics. This significant relationship between external motivation to avoid prejudice and a demographic conceptualization of White racists provides a stark contrast to the results for the psychological factor. Taken together, these findings demonstrate that the belief systems and motivations that predict individuals' own race-related behaviors also color their broader theories about racism. The fact that participants were college-aged Northerners, whereas the demographics they associated with racists included 'old' and 'Southern', provides further evidence that people tend to associate non-self-relevant traits with racism.

\section{Study la}

\section{Method}

College student experimenters approached participants in public (at stores, restaurants, street fairs, office complexes, and an international airport) and asked them to complete the trait questionnaire used in Study 1. Of the 242 individuals who agreed to participate, 189 $(78.1 \%)$ identified as White, $17(7.0 \%)$ as Black, $14(5.8 \%)$ as Asian, $12(5.0 \%)$ were distributed across other racial categories, and 10 (4.1\%) did not indicate race; 105 participants (43.4\%) were female, $136(56.2 \%)$ were male, and $1(0.4 \%)$ did not indicate gender. Participants' age ranged from 18 to 79 , with an average of 37.7 years.

\section{Results and discussion}

As Table 1 indicates, means and standard deviations for the trait ratings were comparable to those in Study 1. Factor analysis was performed on these data using principal components extraction and direct quartimin rotation. Three interpretable factors were again consistent with the evaluative, psychological, and demographic categories identified in Study 1. The composition of the three factors was also comparable to that of Study 1.

\section{Summary of Studies $1 \mathcal{E} 1$ a}

To our knowledge, this is the first investigation to identify the specific content of lay theories of White racism-theories that play a central role in contemporary psychological investigations of prejudice and discrimination. Traits obtained through open-ended questioning about racism were rated by subsequent participants in Studies 1 and 1a, and three factors were found to underlie trait theories of racism: an evaluative 
factor comprising a broad negative stereotype of racists, a psychological factor related to biased belief systems and thought processes, and a factor comprised of nonself-relevant demographic characteristics. Analysis by participant race indicated a tendency for non-White individuals to have a more negative view of the category 'White racist' than Whites, as indicated by higher ratings for the evaluative factor traits. Additional individual differences predicted scores for the latter two factors. Specifically, lower MRS and higher IMS scores were associated with higher scores for the psychological factor, and EMS scores were positively associated with demographic factor scores, consistent with predictions regarding motivations to distance the self from the category 'racist'.

\section{Study 2}

To examine the behaviors associated with White racism, we designed a measure similar to the trait measure of Study 1. More so than traits, though, behaviors often serve as the observable criteria by which determinations of racism are made. Therefore, Study 2 items were phrased as follows: 'A White person who tells jokes about Black people is a racist'. This wording preserved the diagnostic quality that behaviors have for determinations of racism. In contrast to Study 1 , which focused on traits deduced from the label 'racist', Study 2 required participants to use inductive reasoning to judge category membership based on behavioral evidence.

\section{Method}

Behavior generation As in Study 1, we used an open-ended question to generate behaviors associated with racists. Twenty-three college students were asked: 'Think about the category "White racist". What behaviors do you associate with it?' Thirty-seven behaviors were identified by at least three participants, and this list was shown to judges blind to the objectives of the study for clarification and combination of redundant items. This process yielded 29 final items, which can be found in Table 3 (31 items are listed because two items were replaced in Study 2a).
Participants A total of 315 undergraduate psychology students at two universities in the Northeast completed the final questionnaire in mass testing sessions as part of a classroom exercise or in exchange for course credit. Of these students, 199 (63.2\%) identified as White, $22(7.0 \%)$ as Black, $36(11.4 \%)$ as Asian, 36 (11.4\%) were distributed across other racial categories, and $22(7.0 \%)$ did not provide racial information; 147 participants $(46.7 \%)$ were female, $147(46.7 \%)$ were male, and $21(6.7 \%)$ did not indicate gender.

Materials As in Study 1, the final questionnaire had two sections. The behavior section began with the following instructions: 'We are interested in your perceptions of social behavior and your ideas about racism. Please use the scale below to respond to the statements that follow'. A 21-point scale was presented $(1=$ 'strongly disagree', $11=$ 'neutral', 21 = 'strongly agree'), followed by the 29 behaviors in random order, each preceded by the words 'A White person who ...' and followed by '.. is a racist'. The other section of the questionnaire consisted of the MRS, IMS, and EMS. The two sections were counterbalanced to control for order effects. Of all factor and individual difference scores, only Factor 1 scores revealed an order effect. This effect again resulted from disparities in the racial composition of the two order conditions and disappeared when only Whites' responses were analyzed $(t(188)<1)$.

\section{Results and discussion}

Behavior descriptives Means and standard deviations for ratings of the 29 behavior items are presented in Table 3. Interestingly, when asked to list behaviors, participants did not limit themselves to observable actions, but rather provided a broader sample of discriminatory responses including thoughts and preferences. Indeed, examples of stereotyping, prejudice, and discrimination are all represented, a fact which-combined with the subtle nature of some of these behaviors-illustrates that inferences about intent and preference play a large role in lay theories of racism. Comparisons 


\begin{tabular}{|c|c|c|c|c|}
\hline \multirow[b]{2}{*}{ Behavior } & \multicolumn{2}{|c|}{ Study 2} & \multicolumn{2}{|c|}{ Study $2 \mathrm{a}$} \\
\hline & $M$ & $S D$ & $M$ & $S D$ \\
\hline Denies group membership to Blacks on account of race & 19.33 & 3.32 & 19.53 & 3.58 \\
\hline Belongs to a group that promotes racial bigotry & 19.19 & 3.31 & 19.32 & 4.12 \\
\hline Discourages kids from playing with Blacks & 18.04 & 3.66 & 17.70 & 5.03 \\
\hline Believes Blacks are inferior but never says so publicly & 18.04 & 4.18 & 18.10 & 4.97 \\
\hline Thinks Blacks are not suited for certain professions & 17.70 & 4.09 & 18.33 & 4.38 \\
\hline Favors White over Black job applicants & 17.33 & 3.99 & 18.14 & 4.38 \\
\hline Believes in genetic differences in White and Black intelligence & 15.40 & 5.61 & 16.85 & 5.91 \\
\hline Shares biased thoughts with White friends but not the public & - & - & 16.71 & 5.43 \\
\hline Discourages friends/family from marrying a Black person & 14.66 & 5.14 & 15.31 & 5.62 \\
\hline Agrees with societal stereotypes about Blacks & 14.52 & 4.70 & 15.46 & 5.85 \\
\hline Says negative things about Black people but doesn't act on them & 14.43 & 4.80 & 14.48 & 5.81 \\
\hline Prefers not to be around Blacks & 14.38 & 4.95 & 14.29 & 6.37 \\
\hline Uses racial epithets about Black people in conversation & 13.93 & 5.28 & 14.34 & 5.74 \\
\hline Believes Blacks are more likely to commit crimes than Whites & 12.52 & 5.47 & 14.07 & 6.29 \\
\hline Only tries to avoid prejudice because of political correctness & 12.47 & 5.13 & - & - \\
\hline Doesn't care if actions toward Blacks are seen as prejudiced & 12.15 & 6.04 & - & - \\
\hline Supports the flying of the Confederate flag & 11.98 & 5.95 & 12.74 & 6.93 \\
\hline Tells jokes about Black people & 11.27 & 5.36 & 11.79 & 6.48 \\
\hline Thinks slavery so long ago that it is unimportant to talk about & 9.95 & 5.88 & 11.02 & 6.42 \\
\hline Laughs at another person's jokes about Black people & 9.89 & 5.07 & 10.54 & 6.13 \\
\hline Is uncomfortable around Blacks & 9.78 & 4.84 & 10.87 & 6.21 \\
\hline Believes that Blacks are genetically superior athletes & 9.58 & 5.86 & 9.57 & 6.70 \\
\hline Feels anxious around Blacks & 9.09 & 4.85 & 10.54 & 5.82 \\
\hline Believes that prejudice against Blacks is no longer a problem & 8.79 & 5.27 & 9.92 & 5.89 \\
\hline Doesn't speak up or act when someone else is racist & 8.74 & 5.02 & 9.73 & 6.07 \\
\hline Doesn't care if statements are politically incorrect & - & - & 9.29 & 5.96 \\
\hline Has trouble distinguishing Black people from one another & 7.75 & 5.02 & 9.28 & 6.27 \\
\hline Opposes affirmative action & 6.42 & 5.24 & 7.86 & 6.46 \\
\hline Doesn't socialize regularly with Blacks & 6.12 & 4.52 & 6.85 & 5.84 \\
\hline Only has White friends & 6.08 & 4.60 & 6.85 & 5.84 \\
\hline Only dates other White people & 4.27 & 4.49 & 6.67 & 5.95 \\
\hline
\end{tabular}


between White and non-White participants revealed that ratings differed significantly for 11 items, with non-Whites averaging a higher rating in each instance. ${ }^{3}$ This was consistent with predictions, as well as other findings that perceptions of racism often differ by race (e.g. Inman, Huerta, \& Oh, 1998; Rollman, 1978).

Factor analysis Exploratory factor analysis was performed on the behavior data using principal components extraction and direct quartimin rotation. Analysis of the scree plot indicated a three-factor solution accounting for $47.6 \%$ of the variance explained. ${ }^{4}$ Factor loadings from this pattern matrix are reported in Table 4 . Interfactor correlations were .29 for Factors 1 and 2, .46 for Factors 1 and 3, and .24 for Factors 2 and 3. Factor scores were computed using the regression method.

Ten items loaded at .45 or above on Factor 1, which accounted for $31.5 \%$ of the variance explained. The mean response for these items was 8.9 with an average standard deviation of 4.92. ${ }^{5}$ Factor 1 behaviors share the common theme of discomfort/unfamiliarity with Blacks (e.g. 'feels anxious around Blacks', 'has trouble distinguishing Black people from one another'). These behaviors represent a subtle form of racial bias that Gaertner and Dovidio (1986) would suggest is subject to attempts at nonprejudiced justification. For example, a White person who 'only has White friends' might justify that behavior by stating that he lives in a predominantly White neighborhood. Indeed, several White participants annotated their questionnaires with such mitigating explanations.

Nine behaviors reached the .45 cut-off for Factor 2, accounting for $10.9 \%$ of the variance explained. Compared to the subtle behaviors of Factor 1, the Factor 2 behaviors are typical of traditional or overt racism. Unlike trait theories, the structure of participants' behavior ratings did reflect the old-fashioned/modern racism dichotomy popular among psychologists. Overt racism, though, still appears to reign supreme in terms of consensus theories about White racism, as participants' mean rating of 17.0 for these items was much higher than that of the other two behavior factors, and the average standard deviation of 4.13 was the lowest of the three factors. Most laypeople seem to agree that a White person who 'discourages kids from playing with Blacks', 'favors White over Black job applicants', or 'belongs to a group that promotes racial bigotry' constitutes a racist prototype.

Factor 3 had five items and accounted for $5.2 \%$ of the variance explained. The average rating for these items was 9.2 with an average standard deviation of 5.47 , and they share the theme of denial of racism as a continuing problem. Some items are explicit about this viewpoint (e.g. 'thinks slavery is so long ago that it is unimportant to talk about'), whereas other items represent political stances that have been associated with decreased concern regarding discrimination against Black Americans (e.g. 'opposes affirmative action'). This factor, like Factor 1, is consistent with theoretical descriptions of a subtle, modern form of White racism. In fact, 'believes that prejudice against Blacks is no longer a problem' essentially paraphrases an item from the MRS (McConahay, 1986), and various researchers have identified as a central component of modern racists' beliefs the denial of racism as a contemporary social problem (Monteith \& Spicer, 2000).

Individual differences As with the Study 1 factors, behavior factor scores were first regressed on participant race before additional individual difference predictors were added to the model. For the discomfort/unfamiliarity factor, non-White participants were, as expected, more likely than Whites to rate behaviors as indicative of racism $(\beta=-.27, p<.0001)$. The MRS emerged as a negative predictor of scores for this factor $(\beta=-.34, p<.0001)$, and the IMS a positive predictor $(\beta=.29, p<.0001)$; the EMS was not significantly associated with scores for any of the behavior factors $(\beta=.08$ in this case). These data were consistent with the prediction that high-MRS participants would be less likely to label ambiguously biased behaviors as indicative of racism. This suggests that a contributing factor to high-MRS individuals' belief that prejudice is no longer a problem is that 
Table 4. Pattern matrix factor loadings for behaviors associated with racism in Study 2

\begin{tabular}{|c|c|c|c|}
\hline Behavior & $\begin{array}{c}\text { Factor } 1 \\
\text { (discomfort/ } \\
\text { unfamiliarity) }\end{array}$ & $\begin{array}{c}\text { Factor } 2 \\
\text { (overt } \\
\text { racism) }\end{array}$ & $\begin{array}{l}\text { Factor } 3 \\
\text { (denial of } \\
\text { problem) }\end{array}$ \\
\hline Feels anxious around Blacks & .81 & -.10 & .00 \\
\hline Is uncomfortable around Blacks & .71 & .01 & .08 \\
\hline Doesn't socialize regularly with Blacks & .69 & -.24 & .19 \\
\hline $\begin{array}{l}\text { Has trouble distinguishing Black people from one } \\
\text { another }\end{array}$ & .62 & -.01 & .15 \\
\hline Only has White friends & .59 & -.27 & .34 \\
\hline $\begin{array}{l}\text { Believes Blacks are more likely to commit crimes } \\
\text { than Whites }\end{array}$ & .58 & .21 & -.07 \\
\hline Only dates other White people & .54 & -.16 & .19 \\
\hline Prefers not to be around Blacks & .51 & .37 & -.12 \\
\hline Laughs at another person's jokes about Black people & .50 & .24 & .13 \\
\hline Tells jokes about Black people & .45 & .31 & .06 \\
\hline $\begin{array}{l}\text { Only tries to avoid prejudice because of political } \\
\text { correctness }\end{array}$ & .41 & .39 & -.07 \\
\hline Believes that Blacks are genetically superior athletes & .39 & .23 & .13 \\
\hline Discourages kids from playing with Blacks & -.12 & .78 & .13 \\
\hline Denies group membership to Blacks on account of race & -.24 & .77 & .08 \\
\hline Thinks Blacks are not suited for certain professions & -.11 & .70 & .19 \\
\hline Believes Blacks are inferior but never says so publicly & -.04 & .66 & .05 \\
\hline Favors White over Black job applicants & .35 & .60 & -.15 \\
\hline Belongs to a group that promotes racial bigotry & -.04 & .59 & -.06 \\
\hline $\begin{array}{l}\text { Says negative things about Black people but doesn't } \\
\text { act on them }\end{array}$ & .28 & .57 & .03 \\
\hline $\begin{array}{l}\text { Discourages friends/family from marrying a Black } \\
\text { person }\end{array}$ & .15 & .53 & .06 \\
\hline Agrees with societal stereotypes about Blacks & .09 & .52 & .26 \\
\hline $\begin{array}{l}\text { Uses racial epithets about Black people in } \\
\text { conversation }\end{array}$ & .22 & .43 & .12 \\
\hline $\begin{array}{l}\text { Believes in genetic differences in White and Black } \\
\text { intelligence }\end{array}$ & .32 & .36 & .10 \\
\hline $\begin{array}{l}\text { Believes that prejudice against Blacks is no longer a } \\
\text { problem }\end{array}$ & -.02 & .03 & .79 \\
\hline $\begin{array}{l}\text { Thinks slavery so long ago that it is unimportant } \\
\text { to talk about }\end{array}$ & -.02 & .12 & .77 \\
\hline Doesn't speak up or act when someone else is racist & .13 & .08 & .68 \\
\hline Supports the flying of the Confederate flag & -.05 & .09 & .68 \\
\hline Opposes affirmative action & .33 & -.10 & .50 \\
\hline $\begin{array}{l}\text { Doesn't care if actions towards Blacks are seen as } \\
\text { prejudiced }\end{array}$ & .19 & .12 & .35 \\
\hline
\end{tabular}

Notes: $N=315$. Factor loadings of .45 and above are in bold.

they rarely perceive subtle behaviors (such as refusing to socialize with Blacks) as indicative of racial bias. These results also supported the prediction that high-IMS participants would be more prone to viewing subtle behaviors as diagnostic of racism. Just as high-IMS individuals' own race-related behavior is influenced by intrinsic motivations, so too are they likely to 
ascribe an internal motivation to the ambiguously biased behavior of others.

Individual differences were less reliable predictors of Factor 2 scores. Unlike the subtle behaviors of Factor 1 (as well as Factor 3, discussed in more detail below), no differences were indicated between non-White and White participants' scores on the overt racism factor $(\beta=-.00)$. This demonstrates that racial differences in determinations of racism are less prevalent when it comes to judging overt actions typically associated with old-fashioned racial bias, including favoritism toward White job applicants or membership in a group that espouses racism. Such blatant actions are not particularly amenable to nonracial justifications, and most participants seemed to agree that they indicate racism. Further analysis revealed that MRS scores did not predict ratings of these overt racism behaviors $(\beta=.03)$, nor did EMS scores $(\beta=-.08)$. Only the IMS emerged as a significant predictor of scores on this factor, with an internal motivation to avoid prejudice again associated with a greater sensitivity to racism and a lower threshold for labeling behaviors as racist $(\beta=.17, p<.05)$.

As with the ambiguous behaviors of Factor 1, a significant race effect was found for denial of problem factor scores $(\beta=-.14, p<.05)$. NonWhites were once again more likely to associate these behaviors with racism than were Whites, confirming that the less overt a manifestation of racial bias, the more likely it is to lead to between-race-as well as within-race-variance in judgments. The MRS also emerged as a negative predictor of this factor $(\beta=-.40, p<$ $.0001)$, as it had for Factor 1. The MRS was designed to assess subtle racism epitomized by an ideology that minimizes concerns about prejudice, which is consistent with the finding that high MRS scores were associated with low scores on the discomfort/unfamiliarity and denial of problem factors. It is important to note, however, that despite the similar results for participant race and MRS scores across the three behavior factors, these two variables had separate and distinct associations with Factors 1 and 3. That is, even controlling for race, MRS was a significant, negative predictor of participants' ratings of these behaviors. Neither the IMS $(\beta=.10)$ nor EMS $(\beta=-.08)$ emerged as significant predictors of denial of problem factor scores. Once again, though, IMS scores were more positively associated with a propensity for judging behaviors to be indicative of racism than were EMS scores.

\section{Study 2a}

\section{Method}

Participants were solicited in public using the same procedure as in Study 1a. Of the 251 participants, $183(72.9 \%)$ identified as White, 19 $(7.6 \%)$ as Black, $16(6.4 \%)$ as Asian, $20(8.0 \%)$ were distributed across other racial categories, and $13(5.2 \%)$ did not indicate race; 132 participants $(52.6 \%)$ were female, $114(45.4 \%)$ were male, and $5(2.0 \%)$ did not indicate gender. Their age ranged from 18 to 66 , with an average of 35.5 years. To test the reliability of a fourth factor, we replaced two items from the Study 2 questionnaire with new behaviors relevant to norm violation or political incorrectness (see Table 3 for specific items).

\section{Results and discussion}

Means and standard deviations for the behavior items are presented in Table 3. Factor analysis was performed using principal components extraction and direct quartimin rotation. The scree plot indicated a three-factor solution accounting for $50.8 \%$ of the variance explained, and these factors were consistent with the discomfort/unfamiliarity, overt racism, and denial of problem interpretations of Study 2. No substantive differences in factor composition emerged between Studies 2 and 2a.

As in Study 2, a four-factor solution proved interpretable, with behaviors relevant to political incorrectness loading on the fourth factor. Once again, however, the scree plot did not indicate a four-factor solution, and according to Zwick and Velicer (1986), inaccuracies in scree test interpretations tend to be overestimations of the true number of components, not underestimations. Accordingly, the three-factor solution reported herein remains the most reliable characterization of these data. 


\section{Summary of Studies 2 E् $2 a$}

When asked to list behaviors associated with White racism, participants' responses included overt actions as well as beliefs and preferences. This suggests that lay theories of racism are not based solely on observable behavioral criteria, but often rely on inferences drawn about intent and ideology. Unlike trait theories, the structure of theories about racist behaviors does map onto the dichotomy of modern versus oldfashioned racism. Discomfort/unfamiliarity and denial of problem behaviors capture the subtle, ambiguous nature of modern racism. But high ratings and low standard deviations for the overt racism behaviors reveal that they remain prototypes of lay conceptualizations of bias. NonWhite participants and individuals with low MRS scores appeared more sensitive to subtle forms of racism, as they were more likely to deem ambiguous behaviors to be indicative of prejudice. In addition, across factors, the IMS emerged as a better predictor of determinations of racism than the EMS, with IMS scores positively associated with a willingness to infer racist intent and label behaviors as racially biased. This conclusion is consistent with the previous trait results, which suggested that high-IMS individuals tend to view racism as the result of intrinsic factors such as a person's conscious attitudes and preferences (see Table 5 for summary of MRS, IMS, and EMS results across Studies 1 and 2).

\section{General discussion}

The present studies provide an initial examination of lay theories about White racists, a social category of great interest to psychologists, yet one that has escaped empirical analysis. Studies 1 and $1 \mathrm{a}$ identified the specific content of lay theories regarding racist traits. Interestingly, neither the unambiguously negative evaluative factor nor the composition of the psychological factor reflected clear distinctions drawn between modern and old-fashioned racism, a popular dichotomy among contemporary psychologists. Overall, though, the content of the trait factors indicate that when laypeople think about White racism, they tend to focus on overt, old-fashioned forms: participants' psychological impressions of racists consisted of 'fearful of change' and 'old-fashioned', and demographic descriptions included 'Southern' and 'old'. In sum, across two different samples, participants were able to articulate distinct theories about the characteristics associated with racism, demonstrating the appropriateness of approaching this topic from a lay theories perspective.

Studies 2 and 2a comprise a similar investigation of the behavioral bases for lay theories of White racism. An awareness of modern or symbolic racism, as discussed by many psychologists, was demonstrated by those participants who associated discomfort/unfamiliarity and

Table 5. Summary of factor score regressions on MRS, IMS, and EMS (Studies 1 and 2)

\begin{tabular}{llll}
\hline & MRS & IMS & EMS \\
\hline $\begin{array}{l}\text { Study 1 factors } \\
\text { evaluative traits }\end{array}$ & & & $\beta=.06$ \\
$\begin{array}{l}\text { psychological traits } \\
\text { demographic traits }\end{array}$ & $\beta=-.06$ & $\beta=-.01$ & $\beta=.05$ \\
Study 2 factors & $\beta=-.20^{* *}$ & $\beta=.26^{* *}$ & $.20^{* *}$ \\
$\begin{array}{l}\text { discomfort/unfamiliarity behaviors } \\
\text { overt racism behaviors }\end{array}$ & $\beta=.02$ & $\beta=.02$ & $\beta=.08$ \\
denial of problem behaviors & $\beta=-.34^{* *}$ & $\beta=.29 * *$ & $\beta=-.08$ \\
\hline
\end{tabular}

$* p<.05 ; * * p<.01$.

Note: Participant race was also included in the regression model for each study. 
denial of problem behaviors with racism. In fact, many of the items included in these factors are not truly 'behaviors' per se, but rather describe private thoughts, affective responses, and personal preferences. That participants provided such responses to an open-ended question about racism demonstrates that determinations of racial bias depend on more than just observable acts; these are judgments that often involve subjective inferences drawn about intent and motivation (Khan \& Lambert, 2001; Nielsen, 2002). At the same time, the behavior data clearly indicate that blatant, old-fashioned racism remains the prototype for lay theories of White racism. Participants' scores for the overt racism factor were more than twice as high as their ratings for the subtler behaviors, and the average standard deviation was lowest for items in this factor as well. These findings suggest that many of the behaviors that psychologists consider to be indicative of racial bias have not, to this point, entrenched themselves in consensus lay conceptualizations of racism.

\section{Multiple components to lay theories of racism}

These studies suggest that there are multiple components to lay theories of White racism. One aspect of these theories includes subtle, ambiguous forms of bias, and attributes racism to intrinsic antecedents such as political ideology. People who think about racism in this manner tend to cast a wider net in determining what constitutes racism, and are more sensitive to the possibility of bias in general. Another, narrower perspective of White racism does not include examples of subtle bias and describes racists using external characteristics such as demographics. This seems to be a more context-dependent conceptualization, in which people consider mitigating nonracial factors that could account for potentially biased behavior and hold off on making a determination of racism unless the supporting evidence is incontrovertible.

The present research also identifies individual differences that predict how people theorize about racism. Not surprisingly, race was one such variable, particularly for behavior theories. Non-White participants were significantly more likely than Whites to view the subtle behaviors in the discomfort/unfamiliarity and denial of problem factors as indicative of racism. Further evidence of between-race differences in how people think about racism is provided by vignette studies conducted subsequent to the present investigation. In this research, nonWhite participants were more likely to deem the label 'racist' appropriate when an actor was engaged in a behavior from either of these two factors. This result was obtained through comparison of White and non-White college students, as well as using a noncollege sample of 75 White and 65 Black participants (Norton \& Sommers, 2006).

Race was not the only individual difference to predict lay theories of White racism. MRS (McConahay, 1986) scores were negative predictors of the tendencies to rate psychological traits as typical of racists and to perceive subtle behaviors as indicative of racism. These results shed additional light on the nature of the individual difference assessed by the MRS. Beyond variance in political beliefs and personal preferences, a critical distinction between high- and low-MRS individuals involves their sensitivity to subtle forms of racism and their threshold for labeling others as racists. Motivations to respond without prejudice (Plant \& Devine, 1998) also predicted theories of racism. Compared to EMS scores, the IMS was a stronger positive predictor of the tendency to associate behaviors with racism. High IMS scores were also associated with the tendency to think that racism results from stable, intrinsic factors such as ideology. On the other hand, the relationship between EMS scores and behavior ratings was nonsignificant, suggesting the EMS taps into a context-dependent view of racism that takes into account situational factors-contextual information that was absent in the social judgment task required by Study 2 .

\section{Origins and functions of lay theories of racism}

One explanation for these individual difference findings is that certain ways of thinking about social behavior lead to particular ways of theorizing about racism as well as specific scores on the MRS, IRS, and EMS scales. For example, a 
propensity for focusing on situational mitigators of counternormative behavior could lead to both an extrinsic, context-dependent view of White racism as well as high scores on the EMS. However, it is also possible that generalized theories about racism and perceptions of one's own race-related behavior interact to influence one another. The present studies provide preliminary support for the prediction that lay theories of racism serve functions beyond facilitating social perception and understanding; they also seem to allow people to preserve a safe distance between themselves and the category 'racist', as individuals pick and choose aspects of these theories to fit their own psychological needs. Indeed, that participants avoided endorsing aspects of lay theories that included characteristics or behaviors that they themselves were likely to exhibit is consistent with previous findings that people often frame their attitudes in ways that allow for self-distancing from undesirable group affiliations (e.g. Hodson \& Esses, 2002; Pool, Wood, \& Leck, 1998; Wood et al., 1996), unpleasant thoughts (e.g. Schimel et al., 2000), and the appearance of general bias (Ehrlinger, Gilovich, \& Ross, 2005; Pronin, Lin, \& Ross, 2002).

As detailed above, participants' scores on the MRS were negatively correlated with scores for the psychological trait factor, as well as with the discomfort/unfamiliarity and denial of problem behavior factors. These results indicate that high-MRS participants were not less sensitive to the possibility of racial bias across the board, but rather were particularly unlikely to view as racist traits that are often associated with their own social attitudes (e.g. 'old-fashioned', 'fearful of change') and subtle behaviors that are consistent with their political ideology (e.g. 'believes that prejudice against Blacks is no longer a problem'). Support for this selfdistancing hypothesis was also provided by IMS and EMS data. High-IMS participants were particularly likely to describe racists using psychological or ideological traits that they do not possess. Low-IMS individuals, who presumably are more likely to be 'old-fashioned' or 'fearful of change', tended not to include such descriptors in their theorizing about racism. EMS scores were positively correlated with external, demographic trait descriptions. That is, to the extent that participants focused on extrinsic concerns in thinking about their own racerelated behavior, they tended to endorse nonself-relevant demographics in describing White racists in general. These findings suggest that the origins of lay theories of racism are very much intertwined with the development of one's own racial attitudes and motivations. At the same time that people explore and eventually come to embrace various personal ideologies regarding race, so, too, may they be forming more general theories about what racial bias is and what it means to be a racist.

A more direct test of this self-distancing hypothesis would require laypeople to rate the extent to which the traits and behavioral tendencies identified in the present studies are self-applicable. If lay theories of racism serve the function of allowing people to escape personal membership in the category 'racist', self-ratings should exhibit a similar pattern to the results of the present studies. ${ }^{6}$ But even a design such as this would be, as is the case with the present studies, merely correlational. To examine the influence of race-related motivations on general theories about White racism requires manipulation of the salience of internal/external pressures to avoid prejudice. For example, making salient personal concerns about egalitarianism could activate an ideologybased theory of racism and an increased sensitivity to subtle forms of bias. Conversely, salient reminders of normative pressures against prejudice could lead to more context-dependent theories of racism and an increased likelihood of generating non-racist explanations for ambiguously biased behaviors. Such an experimental investigation could provide more conclusive evidence of the self-distancing function of lay theories of racism, as well as demonstrate that endorsement of such theories can change over time or across contexts. It is also worth considering that lay theories may serve different functions for members of different racial groups. A self-distancing function is most likely for Whites, whose race-related behavior is often driven by concerns about appearing racist. 
Members of other racial groups, however, may be more concerned about whether or not others are demonstrating bias towards their group (Sommers \& Ellsworth, 2001; Sommers, in press), and their theorizing about racism could very well reflect this different motivation.

\section{Implications for intergroup relations}

Generally speaking, lay theories are assumed to drive thoughts, feelings, and actions (e.g. Cameron et al., 2001; Hong et al., 2001). The present investigation was designed to examine the content of lay theories regarding White racism, but these theories should also have observable effects on social behavior and intergroup relations. For example, consider someone who believes that racism entails only overt behaviors such as membership in a group that promotes bigotry or actively prohibiting one's family from socializing with people of different races. Such an individual may pursue housing in all-White neighborhoods and oppose policies such as affirmative action without hesitation or concern that doing so will lead to the appearance of racism. In this manner, lay theories of racism have a direct consequence for intergroup relations.

Moreover, concerns about distancing oneself from racism need not be confined to the selfconcept. One interesting issue concerns the impression management strategies that people use in order to convince others that they are not biased. Perhaps one way for individuals to demonstrate compliance with norms against racism would be to show that the traits identified in Study 1 do not apply to their own personalities. Further investigation could address this aspect of race-related impression management by examining how a manipulated threat to one's egalitarian reputation influences the traits and characteristics used to describe the self. The behavior data of Study 2 provide even more concrete suggestions for how people may try to avoid the rejection that accompanies being labeled a racist. Simply demonstrating that you do not, for instance, oppose interracial marriage or belong to a organization that promotes bigotry would probably have little effect because the normative nature of these behaviors should render them nondiagnostic. A more effective strategy for refuting the label 'racist' might be to demonstrate the opposite of one of the subtler behaviors identified in Study 2 in order to establish nonracist 'credentials' (see Monin \& Miller, 2001), such as acting in an overly friendly manner towards Blacks (Norton, Dunn, \& Ariely, 2005). John Rocker again provides an illustrative example. To support his denial of racism, Rocker explained to team officials that he had 'as many good friends on this team that are African-American or Latin as ... Caucasian' ('Rocker apologizes', 1999). The nature and effectiveness of such impression management strategies are important empirical questions for predicting and managing social relationships.

Perhaps the most problematic implication of these studies for intergroup relations is that those people who are most likely to think racist thoughts or commit racist acts are also the people least likely to see these attitudes and actions as racist. The individual difference data on which this conclusion is based are correlational, but the implications of this finding are nevertheless profound. If people who behave in racist ways do not consider those acts to be biased, then attempts at sensitivity training or other prejudice reduction efforts become much more difficult. How can individuals learn to avoid discrimination if they are unable or unwilling to recognize it in their own behavior? How can two people-or groups of peoplediscuss and resolve accusations of racism if they have drastically different ideas of what racism is?

More specifically, at a between-race level of analysis the present studies suggest that nonWhites are more likely to consider subtle forms of bias to be indicative of racism than are Whites. This conclusion is not surprising (see Inman \& Baron, 1996; Johnson et al., 2003), but it has noteworthy consequences, namely that between-race discrepancies in theorizing about racism are fertile ground for real-life racial misunderstandings. The present data suggest that an allegation of bias based on a subtle, ambiguous action is likely to be followed by a denial on the part of that White person 
that his behavior indicates racism. Lay theories about what is and is not racism also help explain why White observers often respond to allegations of subtle bias levied by non-White individuals with skepticism or questions about ulterior motives (Kaiser \& Miller, 2001). The present investigation makes a clear case that allegations and conversations regarding these subtle types of behaviors are ripe for intergroup conflict and controversy, and therefore in need of further empirical examination.

Of course, it is important to note that the present investigation examined lay theories using a context-free paradigm in which participants made judgments in response to a list of traits and behaviors. Given that these studies comprise an exploratory step in the fledgling examination of lay theories of racism, such an investigative strategy proved informative. However, real-life determinations of racism are far more complex and nuanced, as perceivers typically consider mitigating situational factors as well as individuating information about a target. This absence of contextual information in the present stimulus materials provides another explanation for the low overall item ratings for two of the behavior factors in Study 2: perhaps an ambiguous tendency such as socializing exclusively with White people only appears indicative of racism in particular settings, or maybe suggesting that racial prejudice is no longer a problem only seems racist when made in response to clear-cut evidence to the contrary. Clearly, future research needs to include contextual considerations in examining lay theories of racism, as well as experimental designs able to identify the causal impact of these theories on judgment and behavior. Moreover, the present investigation was based on lay theories generated by American college students about White racists in particular. Despite the replication of our factor analysis results using noncollege samples, further generalization across participant samples and types of racial bias is necessary. In particular, it would be useful to recruit larger samples of Black, Latino, Asian, and other non-White participants to examine more fully between-race differences in lay theories regarding White racism.

\section{Conclusion}

Racism, like all topics in psychology, is best understood when analyzed from multiple perspectives. The lay theories approach used in the present investigation offers several novel contributions to this area of research, as well as to the broader literature on intergroup perception and interaction. Accurate knowledge regarding the characteristics and behaviors laypeople associate with White racism is essential for studying intergroup relations and determining what is considered to be acceptable behavior in contemporary society. The present studies also identify ideologies and motivations that predict variability in lay theories about White racism, broadening our understanding of what is truly captured by popular racerelated individual difference measures. More generally, this investigation suggests that the use of lay theories is not limited to attempts to make sense of ambiguous stimuli; lay theories can also serve the function of distancing the self from unpleasant thoughts and social affiliations. In sum, by offering a novel perspective on the traditional perceiver/ target paradigm in research on racism, the present studies shed light on the nature of contemporary race-related norms, motivations, and impression management strategies, and raise additional empirical questions to be considered in the ongoing examination of prejudice and discrimination.

\section{Notes}

1. All factor analyses in Studies 1 and 2 were performed twice: once using only Whites' responses, and once using all participants' responses (a larger sample of non-White participants would have been necessary in order to conduct a meaningful factor analysis of only the responses of these participants). No substantive differences were found between the two factor solutions in either study. Given that this is the first investigation in this exploratory line of research, our principal interest was to identify and examine beliefs about racism held by laypeople in general. In light of this objective, and in order to allow for comparison of factor scores by participant race, the present trait and behavior analyses focus on the factor solutions obtained using the entire sample. 
2. Comparable analyses using participant gender in both Studies 1 and 2 revealed no significant differences when controlling for MRS, IMS, and EMS.

3. These 11 items were (in descending order by mean rating): 'agrees with societal stereotypes about Blacks'; 'believes Blacks are more likely to commit crimes than Whites'; 'only tries to avoid prejudice because of political correctness'; 'laughs at another person's jokes about Black people'; 'believes that Blacks are genetically superior athletes'; 'feels anxious around Blacks'; 'doesn't speak up or act when someone else is racist'; 'opposes affirmative action'; 'doesn't socialize regularly with Blacks'; 'only has White friends'; 'only dates other White people'.

4. A four-factor solution also proved interpretable, though it was not indicated by the scree test. The fourth factor consisted of items related to political incorrectness or violation of social norms (e.g. 'tells racist jokes about Black people', 'uses racial epithets about Black people in conversation'). In order to test the reliability of this fourth factor, we added two relevant items to the Study 2a questionnaire. Analysis confirmed the reliability of the reported three-factor solution.

5. Though Factor 1 (and 3) behaviors were listed by pretesting participants in response to an open-ended question, low means for these items demonstrate a lack of a consensus that these behaviors indicate racism. This finding again underscores the subjective nature of perceptions of racism, and implications for attempts to draw conclusions from the present data are examined in more detail in the general discussion. It is worth recognizing that participants in Study 2 surely made comparisons between items as they completed the questionnaire. For this reason, the unambiguous and blatant nature of Factor 2 items likely drove down mean ratings for Factors 1 and 3 . Had we also included nonracist, control behaviors in this questionnaire, ratings for Factors 1 and 3 would have been pushed higher, perhaps above the scale midpoint. More importantly, Factors 1 and 3 were consistent across two different samples and-in a subsequent set of studies-these behaviors led participants to attribute racist traits and apply the label 'racist' to an actor (Norton \& Sommers, 2006). As such, Factors 1 and 3 are reliable conceptualizations of racism, even if laypeople disagree about the extent to which these behaviors provide conclusive evidence of bias.

6. We are grateful to an anonymous reviewer for this suggestion.

\section{Acknowledgments}

The authors wish to recognize Joel Cooper, Phoebe Ellsworth, Markus Kemmelmeier, Benoît Monin, Leif Nelson, Norbert Schwarz, Joe Simmons, and Oscar Ybarra for their helpful comments on previous drafts of this article. They would also like to thank Kenworthey Bilz and Chris Fletcher for their help with data collection.

\section{References}

Adorno, T., Frenkel-Brunswick, E., Levinson, D., \& Sanford, R. N. (1950). The authoritarian personality. New York: Harper.

Banaji, M. R., Nosek, B. A., \& Greenwald, A. G. (2004). No place for nostalgia in science: A response to Arkes and Tetlock. Psychological Inquiry, 15, 279-310.

Biernat, M., \& Crandall, C. S. (1999). Racial attitudes. In J. P. Robinson, P. R. Shaver, \& L. S. Wrightsman (Eds.), Measures of political attitudes (pp. 297-411). San Diego, CA: Academic Press.

Cameron, J. A., Alvarez, J. M., Ruble, D. N., \& Fuligni, A. J. (2001). Children's lay theories about ingroups and outgroups: Reconceptualizing research on prejudice. Personality and Social Psychology Review, 5, 118-128.

Cattell, R. B. (1966). The scree test for the number of factors. Multivariate Behavioral Research, 1, 245-276.

Crandall, C. S., Eshelman, A., \& O'Brien, L. (2002). Social norms and the expression and suppression of prejudice: The struggle for internalization. Journal of Personality and Social Psychology, 82, 359-378.

Crocker, J., Voelkl, K., Testa, M., \& Major, B. (1991). Social stigma: The affective consequences of attributional ambiguity. Journal of Personality and Social Psychology, 60, 218-228.

Devine, P. G. (1989). Stereotypes and prejudice: Their automatic and controlled components. Journal of Personality and Social Psychology, 56, 5-18.

Dunton, B. C., \& Fazio, R. H. (1997). An individual difference measure of motivation to control prejudiced reactions. Personality and Social Pscychology Bulletin, 23, 316-326.

Ehrlinger, J., Gilovich, T., \& Ross, L. (2005). Peering into the bias blind spot: People's assessments of bias in themselves and others. Personality and Social Psychology Bulletin, 31, 680-692.

Fein, S., Morgan, S. J., Norton, M. I., \& Sommers, S. R. (1997). Hype and suspicion: The effects of pretrial publicity, race, and suspicion on jurors' verdicts. Journal of Social Issues, 53, 487-502. 
Gaertner, S. L., \& Dovidio, J. F. (1986). The aversive form of racism. In J. Dovidio \& S. Gaertner (Eds.), Prejudice, discrimination, and racism (pp. 61-89). Orlando, FL: Academic Press.

Gough, H. G., \& Bradley, P. (1993). Personal attributes of people described by others as intolerant. In P. Sniderman, P. Tetlock, \& E. Carmines (Eds.), Prejudice, politics, and the American dilemma (pp. 60-85). Stanford, CA: Stanford University Press.

Hodson, G., \& Esses, V. M. (2002). Distancing oneself from negative attributes and the personal/ group discrimination discrepancy. Journal of Experimental Social Psychology, 38, 500-507.

Hong, Y., Levy, S. R., \& Chiu, C. (2001). The contribution of the lay theories approach to the study of groups. Personality and Social Psychology Review, 5, 98-106.

Inman, M. L., \& Baron, R. S. (1996). Influence of prototypes on perceptions of prejudice. Journal of Personality and Social Psychology, 70, 727-739.

Inman, M. L., Huerta, J., \& Oh, S. (1998). Perceiving discrimination: The role of prototypes and norm violation. Social Cognition, 16, 418-448.

Johnson, J. D., Simmons, C., Trawalter, S., Ferguson, T., \& Reed, W. (2003). Variation in Black anti-White bias and target cues: Factors that influence perceptions of 'ambiguously racist' behavior. Personality and Social Psychology Bulletin, 29, 609-622.

Kaiser, C. R., \& Miller, C. T. (2001). Stop complaining! The social costs of making attributions to discrimination. Personality and Social Psychology Bulletin, 27, 254-263.

Karpinski, A., \& Hilton, J. L. (2001). Attitudes and the implicit association test. Journal of Personality and Social Psychology, 81, 774-788.

Khan, S. R., \& Lambert, A. J. (2001). Perceptions of rational discrimination: When do people attempt to justify race-based prejudice? Basic and Applied Social Psychology, 23, 43-53.

Kinder, D. R., \& Sears, D. O. (1981). Prejudice and politics: Symbolic racism versus racial threats to the good life. Journal of Personality and Social Psychology, 40, 414-431.

Landrine, H., \& Klonoff, E. A. (1996). The schedule of racist events: A measure of racial discrimination and a study of its negative physical and mental health consequences. Journal of Black Psychology, 22, 144-168.

Levy, S. R., Plaks, J. E,. Hong, Y., Chiu, C., \& Dweck, C. S. (2001). Static versus dynamic theories and the perception of groups: Different routes to different destinations. Personality and Social Psychology Review, 5, 156-168.
Lickel, B., Hamilton, D. L., \& Sherman, S. J. (2001). Elements of a lay theory of groups: Types of groups, relational styles, and the perception of group entativity. Personality and Social Psychology Review, 5, 129-140.

McConahay, J. B. (1986). Modern racism, ambivalence, and the modern racism scale. In J. Dovidio, \& S. Gaertner (Eds.), Prejudice, discrimination, and racism (pp. 91-125). Orlando, FL: Academic Press.

Monin, B., \& Miller, D.T. (2001). Moral credentials and the expression of prejudice. Journal of Personality and Social Psychology, 81, 33-43.

Monteith, M. J., \& Spicer, C. V. (2000). Contents and correlates of Whites' and Blacks' racial attitudes. Journal of Experimental Social Psychology, 36, 125-154.

Nielsen, L. B. (2002). Subtle, pervasive, harmful: Racist and sexist remarks in public as hate speech. Journal of Social Issues, 58, 265-280.

Norton, M. I., Dunn, E. W., \& Ariely, D. (2006). Black is the new White: The persuasive appeal of stigma. Manuscript submitted for publication.

Norton, M. I., Vandello, J. A., \& Darley, J. M. (2004). Casuistry and social category bias. Journal of Personality and Social Psychology, 87, 817-831.

Norton, M. I., \& Sommers, S. R. (2006). Whites' and Blacks' perceptions of racially biased thoughts and behaviors. Unpublished raw data.

Plant, E. A., \& Devine, P. G. (1998). Internal and external motivation to respond without prejudice. Journal of Personality and Social Psychology, 69, 811-832.

Pool, G. J., Wood, W., \& Leck, K. (1998). The self-esteem motive in social influence: Agreement with valued majorities and disagreement with derogated minorities. Journal of Personality and Social Psychology, 75, 967-975.

Pronin, E., Lin, D. Y., \& Ross, L. (2002). The bias blind spot: Perceptions of bias in self versus others. Personality and Social Psychology Bulletin, 28, 369-381.

Rocker apologizes, says he's not racist. (1999, December 23). Retrieved July 21, 2004 from: http://espn.go.com/mlb/news/1999/1222/ 247659.html

Rodin, M. J., Price, J. M., Bryson, J. B., \& Sanchez, F. J. (1990). Asymmetry in prejudice attribution. Journal of Experimental Social Psychology, 26, 481-504.

Rollman, S. A. (1978). The sensitivity of Black and White Americans to nonverbal cues of prejudice. Journal of Social Psychology, 105, 73-77.

Schimel, J., Pyszczynski, T., Greenberg, J., O’Mahen, H., \& Arndt, J. (2000). Running from the shadow: 
Psychological distancing from others to deny characteristics people fear in themselves. Journal of Personality and Social Psychology, 78, 446-462.

Shelton, J. N. (2000). A reconceptualization of how we study issues of racial prejudice. Personality and Social Psychology Review, 4, 374-390.

Sommers, S. R. (in press). On racial diversity and group decision-making: Identifying multiple effects of racial composition on jury deliberations. Journal of Personality and Social Psychology.

Sommers, S. R., \& Ellsworth, P. C. (2000). Race in the courtroom: Perceptions of guilt and dispositional attributions. Personality and Social Psychology Bulletin, 26, 1367-1379.

Sommers, S. R., \& Ellsworth, P. C. (2001). White juror bias: An investigation of racial prejudice against Black defendants in the American courtroom. Psychology, Public Policy, and Law, 7, 201-229.

Swim, J. K., Cohen, L. L., \& Hyers, L. L. (1998). Experiencing everyday prejudice and discrimination. In J. Swim \& C. Stangor (Eds.), Prejudice: The target's perspective (pp. 37-60). San Diego, CA: Academic Press.

Tabachnick, B. G., \& Fidell, L. S. (1996). Using multivariate statistics (3rd ed.). New York: HarperCollins.

Wood, W., Pool, G. J., Leck, K., \& Purvis, D. (1996). Self-definition, defensive processing, and influence: The normative impact of majority and minority groups. Journal of Personality and Social Psychology, 71, 1181-1193.

Zwick, W. R., \& Velicer, W. F. (1986). Comparison of five rules for determining the number of components to retain. Psychological Bulletin, 99, 432-442.

Paper received 9 September 2004; revised version accepted 8 June 2005.

\section{Biographical notes}

SAMUEL R. SOMMERS received his PhD in social psychology from the University of Michigan in 2002 and is currently assistant professor of psychology at Tufts University in Medford, MA. His research examines stereotyping and prejudice, with a particular focus on the role of race-related norms in social perception, judgment, and group dynamics.

MICHAEL I. NORTON received his PhD in social psychology from Princeton University in 2002 and is currently assistant professor of marketing at Harvard Business School in Cambridge, MA. His research focuses on the impact of social norms on judgment, decision-making, and behavior, particularly in the domain of political correctness. 